\title{
Citrus: A Need for its Conservation in Utilising its Medicinal Values through Biotechnological Tools
}

\author{
Priyanka Sharma*, Bidhan Roy, Monish Roy and Gadge Sushant Sundarrao \\ Department of Seed Science and Technology, Uttar Banga Krishi Vishwavidyalaya, \\ Pundibari-736165, Coochbehar, West Bengal, India \\ *Corresponding author
}

\section{A B S T R A C T}

\begin{tabular}{|l|}
\hline Key w o r d s \\
$\begin{array}{l}\text { Citrus, Medicinal } \\
\text { values, in vitro } \\
\text { conservation, } \\
\text { Tissue culture }\end{array}$ \\
\hline Article Info \\
\hline $\begin{array}{l}\text { Accepted: } \\
\text { 30 May } 2020 \\
\text { Available Online: } \\
\text { 10 June } 2020\end{array}$ \\
\hline
\end{tabular}

The citrus plant is found to be potent analgesic, anti-inflammatory, antioxidant, anthelmintic, antibacterial, antifungal agent. Citrus is a significant source of bioactive compounds as the bioactive compounds are suitable for controlling different human diseases. The citrus fruits and their components have a rich source of flavonoids, carotenoids, and bioactive compounds. There is a need for the development of awareness and uses of such compounds in life for saving the life threating diseases by using the bioactive compounds. This manuscript discloses the conservation of the citrus species and its important compounds found in citrus that are highly required by the human body and their use play a significant impact on the human life for disease control. Some of the citrus spp. falls under endangered category. Conservation of the endangered species of citrus needs urgent attention so as to protect the existing genetic diversity and to promote cultivation of these species that are of great relevance in socioeconomic structure of tribal populations of north east India. In view of importance of these species and potential as a future commercial horticulture crops, concentrated efforts are required to collect, characterize and conserve the wild and endangered species of citrus of north-eastern India. These efforts should go along with the major emphasis on developing methods for propagation, multiplication and regeneration of these species under in vitro conditions to facilitate their effective utilization in citrus improvement programmes.

\section{Introduction}

The curiosity in using natural sources or green medicine or medicinal plants is increasing worldwide due to their safety, efficacy, cultural acceptability, and lesser side effects as compared to synthetic drugs. Despite availability of sophisticated, innovative developments of technology and modern medicine, traditional practices are still having prime importance for treating various diseases worldwide including India. The number of people using traditional medicines is rapidly increasing because of many reasons.

Traditional systems of medicine such as Ayurveda, Homeopathy, etc., are gaining popularity and interest throughout the world due to their approaches in preventive and therapeutic measures. Citrus plants are known to possess beneficial biological activities for human health as these plants are easily 
available and show their effect in treatment of various diseases. The genus Citrus contains many economically important fruits that are grown worldwide for their high nutritional and medicinal value (Su et al., 2014). Fruits of this genus are promising source of Vitamin C, carotenoids, coumarins, folate, and flavonoids. Vitamin $\mathrm{C}$ is reported as an antiscorbutic and possesses antioxidant properties. Flowers and leaves of Citrus are usually strong scented, the extracts of which contain many useful flavonoids and other compounds that are effective insecticides, fungicides, and medicinal agents (Mabberley et al., 2004). Therefore, citrus fruits could be categorized as functional foods containing components shown to have health promoting and anticancer activities.

On the other hand, plant tissue culture represents the most promising areas of application at present time and giving an out look into the future. Tissue culture of citrus spp. is very important to increase the production and mass propagation of this valuable plant. The use of tissue culture in the breeding of citrus spp. is essential as it has the potential to overcome infertility of citrus seeds due to fungal infections by Fusarium, Rhizoctonia, and Sclerotium. Fungal infections caused the citrus seeds to be damaged before they can be germinated (Hume et al., 1957). Citrus is generally propagated through budding, cutting, or layering. Therefore, propagation is limited to the period when buds are available (Rathore et al., 2007). The areas ranges from micropropagation of ornamental and forest trees, production of pharmaceutically interesting compounds, and plant breeding for improved nutritional value of staple crop plants, including trees to cryopreservation of valuable germplasm. All biotechnological approaches like genetic engineering, haploid induction, or somaclonal variation to improve traits strongly depend on an efficient in-vitro plant regeneration system. The rapid production of high quality, disease free and uniform planting stock is only possible through micropropagation. New opportunities has been created for producers, farmers and nursery owners for high quality planting materials of fruits, ornamentals, forest tree species and vegetables. However micropropagation technology is expensive as compared to conventional methods of propagation by means of seed, cuttings and grafting etc. Therefore it is essential to adopt measures to reduce cost of production. Plant tissue culture is a decent approach to obtain these substances in large scale. Plant cell culture has made great advances. Conceivably the most significant role that plant cell culture has to play in the future will be in its association with transgenic plants. Slow growth in vitro storage and cryopreservation are being anticipated as solutions to the problems inherent in field gene banks. If possible, they can be used with field gene banks, thus providing a secure duplicate collection. They are the means by which future generations will be able to have access to genetic resources for simple conventional breeding programmes, or for the more complex genetic transformation work. As such, it has a great role to play in agricultural development and productivity.

\section{Propagation}

Citrus can be propagated by many methods including ex vitro such as seeds, cuttings, airlayering, grafting etc. or in vitro such as tissue culture. Although some cultivars can be reproduced by seed, this method is considered inferior. Varieties that are reproduced by seed requires more time to produce fruit, susceptible to diseases, difficult to keep true to type and tend to produce more thorns than grafted varieties. Tissue culture and micropropagation protocols have been described for a number of citrus species and 
explant sources Barlass and Skene, (1982); Duran-Vila et al., (1989); Raman et al., (1992); Normah et al., (1997); Chakravarty and Goswami (1999); Al-Khayri and AlBahrany (2001); Filho et al., (2001) Usman et al., (2005).

\section{Techniques of plant tissue culture}

\section{Micropropagation}

Production of large number of vegetative progeny through plant tissue culture is called micropropagation. Sexually propagated plants (through generation of seeds) demonstrate a high amount of heterogeneity since their seed progenies are not true to type. Asexual reproduction (by multiplication of vegetative parts) gives rise to genetically identical copies of parent plant. Thus it permits perpetuation of the parental characters of the cultivars among the plants resulting from micropropagation. In vitro micropropagation technology can overcome some constraints to citrus improvement, cultivation, increases fruit quality and resistance to disease and environmental stresses (Grosser et al., 1994). Micropropagation is an important asexual method that can be used for the production of virus - free rootstock plants (Roistacher et al., 1976).

Virus and viroids have been recognised as serious problem limiting the vigour, yield, quantity and quality. Severe infections have resulted in the exclusion of some cultivars from commercial usage, reported that viral diseases are major threats affecting citrus industry (Vishwanath and Narayan, 2015).

The diseases are graft - transmissible through grafting infected bud sticks (Santos et al., 1984). Hence, rising of disease - free foundation plants is imperative to provide certified bud sticks to the growers and to encourage the planting of grafts instead of seedlings (Mukhopadhyay et al., 1997). The elimination of viruses, viroids, and phytoplasmas from infected initial (mother) propagation material is a prerequisite for the production of healthy, vegetatively propagated crop material. Methods used are thermotherapy, meristem tissue culture, in vitro micrografting, in vitro chemotherapy, and cryotherapy of shoot tips, followed by shoot - tip tissue culture or in vitro micrografting (Christina, 2015).

The micrografting technique was first used for the elimination of viruses and viroids in citrus by Navarro et al., 1976. The use of tissue culture methods for citrus crop species has already had practical benefits. Most notable among these are techniques for obtaining virus - free and mycoplasma - free stocks using in vitro grafting of apical meristems from infected plants onto decapitated seedlings (Navaro et al., 1975). Citrus also stands among difficult to root crops and micropropagation offers rapid propagation of such crops in limited space and time under controlled conditions throughout the year (Usman, 2005). The micropropagation of citrus has always aroused great interest among scientists. There is a growing demand to develop new varieties of plants resistant to pathogens and adverse environmental conditions and characterized by high quality of fruits (Yaacob et al., 2014). Citrus (Lemons) plantations face a number of problems such as pests, slow growth, susceptibility to disease, sensitivity to low temperatures, and substantial losses during storage (Mukhtar et al., 2005, Savita et al., 2010, Sarma et al., 2011). In vitro culture is a technique that can solve these problems. In addition, this technique can also produce crops on a relatively large scale in comparison with traditional plant breeding. Furthermore, in vitro cultures eliminate infections and can be faster than traditional plant cultures (Savita et al., 2011; Singh and Kaur, 2011). 


\section{Application of micropropagation}

\section{Commercial production of secondary metabolites}

Alkaloids, terpenoids, phenyl propanoids etc. with various biological activities like antimicrobial, antibiotic, insecticidal, valuable pharmacological and pharmaceutical activities are common examples of secondary metabolites.

\section{Production of synthetic seeds}

The plant propagules are mixed in sodium alginate solution in a petriplate. Calcium chloride is taken in a beaker of $100 \mathrm{ml}$ capacity. The plant propagules along with sodium alginate with the help of a dropper are dropped into the calcium chloride solution. The beads are kept in calcium chloride for 1520 minutes for solidification. The excess calcium chloride is decanted and the encapsulated beads are washed with sterilized distilled water. Thus the synthetic seeds are ready for preservation or transport or germination (Roy, 2010) (Figure 1).

\section{Production of disease free plants}

Micropropagation provides a rapid method for production of pathogen free plants. In case of viral diseases especially the apical meristem of infected plants are free or carry very low concentration of viruses. Thus culturing meristem tips provides disease free plants. Potential of cell to divide and develop into multicellular plants is termed as cellular totipotency (Rajput, 2019).

\section{Tissue culture in citrus}

In vitro propagation studies of Citrus jambhiri Lush. had the objective to develop a protocol for plantlet regeneration from callus. Thus in vitro culture techniques are adopted for quick propagation of medicinally important endangered citrus species. Regeneration from callus gives a way to rectify the problem of explants shortage. Kaur (2018) developed an efficient protocol for in vitro embryogenic callus induction and regeneration of Rough lemon (Citrus jambhiri Lush.) and reported that when MS medium was fortified with NAA $(0.5 \mathrm{mg} / \mathrm{l})$ and combined with BAP (3.0 $\mathrm{mg} / \mathrm{l})$ and kinetin $(1.0 \mathrm{mg} / \mathrm{l})$ had good regeneration potential, highest number of shoots and shoot length and took minimum number of days for regeneration.

Similarly, Kumar et al., (2011) reported that maximum shoot regeneration $(76.09 \%)$ and number of shoots (8.15) per callus was observed when full MS medium was supplemented with NAA $0.5 \mathrm{mg} /$ litre + kinetins $0.5 \mathrm{mg} /$ litre + BA $3.0 \mathrm{mg} /$ litre. But average length of regenerated shoots was highest $(4.32 \mathrm{~cm})$ when calli was cultured on full MS medium supplemented with NAA 0.5 $\mathrm{mg} / \mathrm{litre}$, kinetin $0.5 \mathrm{mg} / \mathrm{litre}$ and BA $1.0 \mathrm{mg} / \mathrm{litre}$.

Amin and Shekafandeh (2015) also concluded that among the three explants such as nodal segments, leaf and root segments, nodal segments has been considered as the best explants for induction of callus since the calli derived from the nodal segments were green and friable as compared to the leaf and root segments and the callus derived from the leaf segments appeared to be brown and necrotic and when MS medium was supplemented with $0.5 \mathrm{mg} / 1$ 2, 4-D induced maximum embryogenic calli of mexican lime. According to Jamilah et al., (2014), Citrus assamensis can be regenerated and propagated through tissue culture technique, as young stem appeared to be the most responsive explant type and the highest shoot formation (46.7\%) was observed when MS medium was supplemented with $1.5 \mathrm{mLL}^{-1} \mathrm{NAA}$ and $2.0 \mathrm{mgL}^{-1} \mathrm{BAP}$. 


\section{Tissue culture in pharmaceuticals}

Plant cell and tissue cultures hold great promise for controlled production of innumerable useful secondary metabolites (Vijayasree et al., 2010). Plant cell cultures combine the merits of whole-plant systems with those of microbial and animal cell cultures for the production of valuable therapeutic secondary metabolites (Hellwig et al., 2004). In the search for alternatives to production of medicinal compounds from plants, biotechnological approaches, specifically plant tissue cultures, are found to have potential as a supplement to traditional agriculture in the industrial production of bioactive plant metabolites (Ramachandra et al., 2002). Exploration of the biosynthetic capabilities of various cell cultures has been carried out by a group of plant scientists and microbiologists in several countries during the last decade (Siahsar et al., 2011)

\section{Natural production of phytochemicals occurred in citrus}

Phytochemicals constitute one of the most numerous and widely distributed groups of substances in the plant kingdom. Plants produce chemicals known as secondary metabolites that are not directly involved in the process of growth but acts as deterrents to insects and microbial attack. Phytochemicals that possess many ecological and physiological roles are widely distributed as plant constituents. There are about 40 limonoids in citrus with limonin and nomilin being the principal ones (Craig, 2002). These compounds, which occur in high concentration in grapefruit $(C$. vitis $)$ and orange juice $(C$. sinensis) partly, provide the bitter taste in citrus.

\section{Limonoids}

Limonoids possess the ability to inhibit tumor formation by stimulating the enzyme glutathione S-transferase (GST). Citrus pulp and the albedo (the white of the orange) is rich in glucarates. These substances are being studied extensively for their potentials in preventing breast cancer and to lower the risk and symptoms of premenstrual syndrome (Craig, 2002).

\section{Flavonoids}

Flavonoids are another phytochemicals found in citrus fruits. The flavonoids have strong inherent ability to modify the body's reaction to allergens, viruses and carcinogens. They show anti-allergic, anti-inflammatory, antimicrobial and anti-cancer activity. These flavonoids are responsible for the bitter taste of some grape fruits, lemons and oranges.

\section{Quercetin}

Quercetin is a flavonoid and more specifically a flavonol that constitutes the aglycone of the glycoside rutin. Among all the flavonoids, Quercetin is found to be the most active and due to this reason, many medicinal plants owe much of their activity due to their high quercetin content. Quercetin has demonstrated significant anti-inflammatory activity because of direct inhibition of several initial processes of inflammation. Quercetin may have positive effects in helping to prevent cancer, prostatitis, heart diseases, cataracts, allergies/inflammations and respiratory diseases such as bronchitis and asthma (Yano et al., 1999).

\section{Rutin}

Another useful citrus flavonoid glycoside is rutin and it is also known as rutoside or quercetin-3-rutinoside. In humans, rutin attaches to the $\mathrm{Fe} 2+$ ion and it is preventing it from binding to hydrogen peroxide and creating a highly reactive free radical that may damage cells. It is also an antioxidant and therefore, it plays an important role in inhibiting some cancers. 


\section{Tangeritin}

Tangeritin is a polymethoxylated flavone that is found in tangerine and other citrus peels.

\section{Carotenoids}

Another group of phytochemicals found in citrus are carotenoids. Pink grapefruit have a high content of beta carotene while other citrus fruits such as tangerines and oranges contain high levels of other carotenoids (lutein, zeaxanthin, cryptoxanthin) (Mangels et al., 1993) that have significant anti-oxidant activity. These carotenoids are associated with a lower incidence of age-related mascular degeneration, the leading cause of blindness in human after the age sixty five (Seddon et al., 1994). Pink grapefruit also contains a high level of lycopene, the red pigment that has a significant anti-tumor activity.

\section{Ascorbic acid}

The fruit juice contained ascorbic acid, niacin, riboflavin and thiamin in varying quantities. Ascorbic acid in the body aids in iron absorption from the intestines.

It is necessary as an anti-stress and protector against cold, chills and damp. It prevents muscle fatigue and scurvy that is characterized by skin hemorrhages, bleeding gums, fragile bones, anemia and pains, joints and defects in skeletal calcification (Okwi et al., 2006).

It also acts as antioxidants in the skin by scavenging and quenching free radical generated by ultra violet radiation stabilization. The production of collagens is also dependent on vitamin $\mathrm{C}$. It helps in the promotion and restoration of skin and improvement of fine wrinkles.

\section{Phytochemicals in citrus on curing various diseases of humans}

\section{Cancer}

The colon cancer is a serious issue caused by the imbalances and wrong uses of diet. Mostly $90 \%$ cases of colon cancer have reported in the world due to diet. The tyrosine modulator as citrus flavonoids is useful in cancer treatments. Several studies reported that in treatments of different cancers lines, the juice of citrus showed an antiproliferative. The role of flavonoids (nobiletin, hesperetin, tangeretin and neohesperetin) is tumor controlling activity in the human body. The citrus peel oil like dlimonene showed an anti-cancerous activity, especially peel oil of citrus effective in skin cancer control. The bioactive compounds isolated from seeds of Citrus aurantifolia were found to posses the potential of inhibiting human pancreatic cancer cells. While, the compounds purified from peel had the potential of suppressing the colon cancer cells. Citrus aurantifolia fruit volatile oil showed 78\% inhibition of human colon cancer cells (SW-480) with $100 \mathrm{~g} / \mathrm{ml}$ concentration at $48 \mathrm{~h}$. Limonene, one of the main constituents of citrus species fruit, reduces the risk of mouth, skin, lung, breast, stomach and colon cancer. Hesperidin, and its flavone analogue, diosmin, also exerted anticarcinogenic activities in various in vivo studies.

Oxidative damage, cardiovascular and coronary heart diseases (CVD and CHD)

These are the safe and sound methods required for the isolation of citrus new bioactive compounds in juice, peel rag, and seeds. The chronic, haemorrhoids and leg cancer, the 6,8-di- $C$-glucosyldiosmetin and Vicenin-2 suppressive of blood adhesion molecules are mostly found in citrus. 
The different citrus extracts were used for the significant control of haemorrhages. The principal role of flavonoids chrysin, luteolin and 7-hydroxyflavone is to induce on the umbilical vein, the lipoprotein. The bioactive compounds are better for hypercholesterolemia and atherosclerosis control.

\section{Anti-microbial activity}

Citrus fruit is a rich resource of flavonoids with many physiological properties involved in controlling antiviral activity and antimicrobial activity. Hesperidin and quercetin involve in control of herpes virus, parainfluenza and polioviruses (Kim et al., 2003). The sweet oranges and grapefruit is a rich source of phytochemicals, suitable for microbial control.

\section{Antioxidant activity}

Vitamin $\mathrm{C}$ is predominant in C. aurantifolia and it acts as antioxidant both in vitro and in vivo.

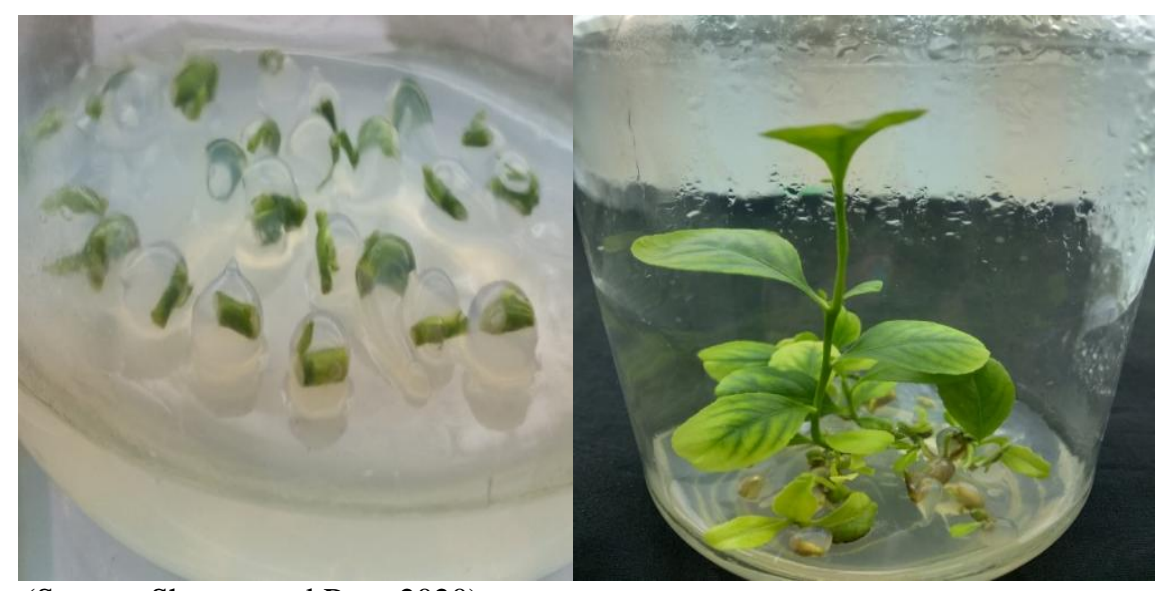

(Source: Sharma and Roy, 2020)

Fig.1 Synthetic seeds prepared from in vitro grown shoot tips of Citrus Jambhiri Lush

\section{Activity against other diseases}

Citrus has a precious resource of soluble and insoluble fiber with several benefits in preserving and removal of toxic effects in the body (Pragasam et al., 2013). Fiber improves the gastric adsorption in the small intestine like the gastric emptying, reduces the energy absorption process, the bile duct and liver maintaining (Andreotti et al., 2008).

\section{Effects on the bone}

The administration of citrus extracts increased the trabecular bone mineral content, and bone mineral density of tibia, improved the levels of phosphorus and calcium.

\section{Other effects}

Citrus fruits are highly recommended for persons suffering from kidney stones, gout and arthritis. C. aurantifolia juice contains potassium citrate which prevents the formation of kidney stones and eases their dissolution (Roger GDP, 2002). Due to the high content of vitamin $\mathrm{C}$, citrus fruits are used in the treatment of scurvy. The antiscurvy effect of citrus fruits is very strong because of the balanced composition of organic acids and minerals (Okwu, 2008).

Currently there is a worldwide increasing interest in herbal medicines accompanied with increased laboratory investigations into the 
pharmacological properties of the bioactive ingredients and their ability to treat various diseases. The phytoconstituents which are present in the citrus are mainly coumarins and flavonoids which are responsible for the actions. There is a need for the development of awareness and uses of such compounds in life for saving the life threating diseases by using the bioactive compounds.

The phytochemical constituents and isolated bioactive compounds of citrus genus can be investigated further to achieve further leading in developing new herbal drug through reverse pharmacological approaches for treatment of various chronic diseases such as liver diseases, arthritis, cancer, and other inflammatory diseases. Therefore in order to utilise its medicinal values for human consumption, there is a need to conserve the endangered species of citrus, thereby practising certain biotechnological tools such as in vitro culture which has a unique role in sustainable and competitive agriculture and forestry and has been successfully applied in plant breeding for rapid introduction of improved plants.

Plant tissue culture has become an integral part of plant breeding. It can also be used for the production of plants as a source of edible vaccines as well as many useful plant derived substances which can be produced in tissue cultures can also be used further by the human beings in treating life threating diseases. Therefore, further research may be carried out on citrus to explore their full therapeutic activity.

\section{References}

Al-Khayri J M and Al-Bahrany A M (2001). In vitro micropropagation of Citrus aurantifolia (lime). Current Sci., 81:12421246.

Amin H and Shekafandeh A (2015) Somatic embryogenesis and plant regeneration from juice vesicles of Mexican lime (Citrus aurantifolia L.). Jordan J Agric Sci., 11(2): 495-505.

Andreotti, Ravaglia C, Ragaini D and Costa A G (2008). Phenolic compounds in peach (Prunus persica) cultivars at harvest and during fruit maturation. Annals Appl. Bio., 153:11-23.

Barlass M and Skene K G M (1982). In vitro plantlet formation from citrus species and hybrids. Sci Hortic., 17:333341.

Chakraborty B and Goswami B C (1999). Plantlet regeneration from long-term callus cultures of Citrus acida Roxb. and the uniformity of regenerated plants. Sci Hortic., 82: 159-169.

Christina V, Varvara I M, Theodora K and Isaia I (2015). Principles for supplying virus tested material. Adv in Virus Research 91: $1-32$.

Craig E J (2002). Phytochemical Guardians of Our Health, J. Am Dietetic Assoc 97(2): 199-204.

Duran-Vila N, Ortega V and Navarro L (1989) Morphogenesis and tissue cultures of three Citrus species. Plant Cell Tiss Org Cult., 16:123-133.

Filho J C B, Kobayashi A K, Peirera L F P, Hissano Z and Vieira L G E (2001). Invitro adventitious shoot regeneration from sweet orange using thin epicotyls sections. Crop Breeding and Appl. Biotechnol., 1: 27-34.

Grosser J W (1994). "In vitro culture of tropical fruits," in Plant Cell and Tissue Culture, K. Vasil and T. A. Thorpe, Kluwer Academic Publishers, Dordrecht, The Netherlands. Eds. 475- 496.

Hellwig S, Drossard J, Twyman R M and Fischer $R$ (2004). Plant cell cultures for the production of recombinant proteins. Nat. Biotechnol., 22: 1415- 1422.

Hume H H (1957). Citrus Fruits (Revised Edition of Cultivation of Citrus Fruits), Macmillan, New York, NY, USA.

Jamilah S Y, Mahmad N, Taha R M, Mohamed, Yussof A I M and Saleh A (2014). Optimization of Culture Conditions (Sucrose, pH, and Photoperiod) for In Vitro Regeneration and Early Detection of 
Somaclonal Variation in Ginger Lime (Citrus assamensis) Scientific World J., 110.

Kaur S (2018). In vitro somatic embryogenesis and regeneration from epicotyls segments of rough lemon (Citrus jambhiri Lush.). Int. J of Chem Stud., 6(1): 2082-2091.

Khalid H, Nisar M, Majeed A, Nawaz K and Bhatti K (2010). Ethnomedicinal survey for important plants of Jalalpur Jattan, District Gujrat, Punjab, Pakistan. Ethnobot Leaf., 14:807-25.

Kim D O, Jeong S W and Lee C Y (2003). Antioxidant capacity of phenolic phytochemicals from various cultivars of plums. Food Chemistry 81:321-326.

Kumar K, Kaur H, Gill M I S, Rattanpal H, Kanika S and Gosal S S (2011). An efficient regeneration protocol from callus culture in rough lemon (Citrus jambhiri Lush.). Indian J Agri Sci., 81(4):324-329.

Mabberley D J (2004). "Citrus (Rutaceae): A review of recent advances in etymology, systematics and medical applications," Blumea: J Plant Taxonomy Plant Geography., 49 (2-3): 481-498.

Mangels A R, Holden J M and Beecher G R (1993). Carotenoid Content of Fruits and Vegetables, an Evaluation of Analytic Data, J. Am Dietetic Assoc 93:284-296.

Mukhopadhyay S J, Raj B C, Sharma A Gurung R $K$ and Nath P S (1997). Micropropagation of Darjeeling orange (Citrus reticulata Blanco) by shoot-tip grafting. J of Hortic Sci and Biotechnol 72(3): 493 - 499.

Mukhtar, Khan R M M, Fatima B, Abbas M and Shahid A (2005). "In vitro regeneration and multiple shoots induction in Citrus reticulata (Blanco)." Int J Agri Biol., 7: 414-416.

Navarro L Roistacher C N and Murashige T (1975). Improvement of shoot-tip grafting in vitro for virus free Citrus. $J$ of the Am Soc for Hortic Sci., 100: 471 - 479.

Navarro L, Roistacher C N and Murashige $\mathrm{T}$ (1976).Effect of size of shoot tips on psorosis - A and exocortis content of navel orange plants obtained by shoot-tip grafting in vitro. In Proceedings of the seventh IOCV conference., Pp. 194-197.

Normah M N Hamidoh S and Ghani F D (1997).
Micropropagation of Citrus halimii-an endangered species of South-east Asia. Plant Cell Tissue Org Cult., 50: 225-227.

Okwi D E and Emenike I N (2006). Evaluation of the Phytonutrients and Vitamins Contents of Citrus Fruits. Int J. Mol. Med. Adv Sci., 2(1) 1-6.

Okwu D E (2008). Citrus fruits: a rich source of phytochemicals and their roles in human health: a review. Int J Chem Sci., 6(2): 451-471.

Pragasam S J and Rasool M (2013). Dietary component p-coumaric aci suppresses monosodium urate crystal-induced inflammation in rats. Inflammation Res., 62: 489-498.

Rajput R S (2019). Instant Plant Breeding and Seed Technology: A readymade material for competitive exam. Jain brothers, New Delhi, 1:154-165.

Ramachandra S R and Ravishankar G A (2002). Plant cell cultures: Chemical factories of secondary metabolites. Biotechnol. Adv., 20: 100-153.

Raman H, Gosal S S and Brar D S (1992). Plant regeneration from callus cultures of Citrus limon and C. jambhiri. Crop Improve, 19:100-103.

Rathore J S, Rathore M S, Singh M, Singh R P and Shekhawat N S (2007). "Micropropagation of mature tree of Citrus limon," Indian Journal of Biotechnology, 6(2): 239-244.

Roger GDP (2002). Encyclopedia of Medicinal Plants. Education and Health Library Ed 153-154.

Roistacher C N, Navarro L and Murashige T (1976). Recovery of citrus selections free of several viruses, exocortis viroid and spiroplasma citri by shoot-tip graft-ing in vitro. Proceedings 7 th Conference Int. Organization Citrus Virologists, IOCV, Riverside., 186-193.

Roy B (2010). Synthetic seed: A challenging Technology in Plant Propagation, Transportation and Conservation. Lambert Publishing., Pp. 85-99.

Santos, Filho H P, Paguio O R, Coelho Y S and Medina V M (1984). The Citrus variety improvement program in Brazil. Fifth Int. 
Citrus Congress. 2: $235-237$.

Sarma C, Borthakur A, Singh S, Mod M K and Sen P (2011). Efficient in vitro plant regeneration from cotyledonary explants of Citrus reticulata L. Blanco. Annals Bio Res., 2(6): $341-348$.

Savita, Vijay G S. Virk and Nagpal A (2010). Effect of Explant Type and Different Plant Growth Regulators on Callus Induction and Plantlet Regeneration in Citrus jambhiri Lush. Environ. We Int. J. Sci. Tech 5:97-106.

Savita, Virk G. S, Nagpal A (2011). In vitro selection of calli of Citrus jambhiri Lush. for tolerance to culture filtrate of Phytophthora parasitica and their regeneration. Physiol. Mol. Bio Plants, 17: 41-47.

Seddon J M, Ajani A and Sperduto R D (1994). For the Eye Disease Case-Control Study Group, Dietray Carotenoids, Vitamin A, $\mathrm{C}$, and $\mathrm{E}$ and Advanced Age-Related Macular Degeneration. JAMA, 271: 14131430.

Siahsar B, Rahimi M, Tavassoli A and Raissi A S (2011). Application of Biotechnology in Production of Medicinal Plants. J. Agric. \& Environ. Sci., 11(3): 439-444.

Silalahi J (2002). Anticancer and health protective properties of citrus fruit components. Asia Pac J Clin Nutr 11:79-84.

Singh B and Kaur A (2011). Comparison of agar and gum karaya as gelling agent for in vitro regeneration of rough lemon (Citrus jambhiri Lush.) plantlets from nodal explants. J Crop Sci Biotechnol., 14(4):
$297-303$.

Su H J, Hogenhout S A, Al-Sadi A M and Kuo C H (2014). "Complete chloroplast genome sequence of omani lime (Citrus aurantiifolia) and comparative analysis within the rosids," PLOS ONE, 9 (11): Article ID e113049.

Suryawanshi J (2011). An overview of Citrus aurantium used in treatment of various diseases. Afr J Plant Sci 5:390-5.

Usman M, Muhammad S and Fatima B (2005). In vitro multiple shoot induction from nodal explants of Citrus cultivars. J Central Eu Agric., 6:435-442.

Vijayasree N, Udayasri P, Aswani K Y, Ravi B B, Phani K Y and Vijay V M (2010). Advancements in the Production of Secondary Metabolites. J. Nat. Prod., 3: 112-123.

Vishwanath W and Narayan P (2015). In Vitro Multiplication of important horticultural Plant Cirus reticulata Blanco. Int. J of Pharm. Bio Sci., 6(1) (B): 1275 - 1280.

Yaacob J S, Mahmad N, Taha R M, Mohamed N, Yussof A I M and Saleh A (2014). Optimization of culture conditions (sucrose, $\mathrm{pH}$, and photoperiod) for in vitro regeneration and early detection of somaclonal variation in ginger lime (Citrus assamensis). The Sci. World J., 10: 1-9.

Yano M, Kawaii S, Tomono Y, Katase E and Ogawa K (1999). Quantification of Flavonoid Constituent in Citrus Fruits. $J$. Agri Food Chem., 47:3565-3571.

\section{How to cite this article:}

Priyanka Sharma, Bidhan Roy, Monish Roy and Gadge Sushant Sundarrao. 2020. Citrus: A Need for its Conservation in Utilising its Medicinal Values through Biotechnological Tools. Int.J.Curr.Microbiol.App.Sci. 9(06): 3825-3834. doi: https://doi.org/10.20546/ijcmas.2020.906.453 